been allowed to fall. Such statements as ' as these' (fructoses and pentoses) ... ' do not need to be phosphorylated some easement of diabetic metabolism occurs' may impress the reader but it can be seen that Dr. Todd's main concern is to advocate a line of treatment which is not the orthodox one. Later in the book when writing about such conditions as 'False Phthisis' and 'False Heart Disease' he states that the offending demon lies in the duodenum.

A large number of Dr. Todd's patients seem to be treated on a' 'Fat-Low Diet.' Many others receive injections of colloidal sulphur and hexamine. The diabetics get synthalin and mist. diabetica. Asthmatics are given morphia and heroin. Morning exercises, both inside and outside the lavatory, are prescribed for the costive. Dr. Todd's cancer patients receive radio-active selenide.

The appendices to this book contain specimen diet sheets. Such instructions as : 'In cooking use butter only, not lard, dripping, oil, suet or margarine' should make Mr. Strachey weep crocodile tears. There is also a list of prescriptions and formulae at the end of the book, one such prescription contains I I separate ingredients.

This book can only be recommended to the post graduate with a critical mind.

J.M.N.

\section{THE STORY OF ST. THOMAS'S, 1106-1947}

By Charles Graves. Distributed by Faber \&

Faber Ltd. for St. Thomas's Hospital. 1947.

$\mathrm{Pp} .72$ with 8 plates in colour and $4 \mathrm{I}$ illustrations in black and white. Price 8s. 6d.

As nationalization of the Nation's medical services draws closer, many institutions with long and distinguished histories are wondering how far they will be allowed to retain their individual characteristics. St. Thomas's Hospital has produced a brief but liberally illustrated history, having entrusted the writing of the text to Charles Graves. This book is charmingly designed and will delight the heart of Thomas's men and women wherever they may be.

The numerous illustrations, many of which are in colour, are finely reproduced and it is noted that the book was printed in Czechoslovakia. St. Thomas's was founded in 1106 and as this volume is dedicated to the Hospital of the future, we wish them another 800 years as distinguished and successful as the last.

\section{S.H.T.}

\section{THE PARATHYROID GLANDS AND SKELETON IN RENAL DISEASE}

By J. R. Gil.mour, M.R.C.P. Geoffrey Cumberlege, Oxford University Press. 1947. Pp. 157. Price I 8s.

In this short monograph the author has collected together part of his work on the pathology of the parathyroid glands on which he has been engaged for a number of years. It is based on an investiga- tion of ninety cases of renal disease of all kinds except ischaemic atrophy. The parathyroid glando were studied in all these cases; the skeleton was studied in thirty-three, including seven cases of renal rickets, and the author gives very detailed histological descriptions of the skeleton in five of these cases. There is a chapter on metastatic calcification and calcinosis and the book ends with an appendix in which the individual cases are summarized. Each chapter includes a critical survey of the literature.

This book will be invaluable to all workers in this field of morbid anatomy, but it is for the specialist only and contains little which will be of interest to the clinician.

H.A.M.

\section{THE SECRET INSTRUMENT (the birth of the Midwifery Forceps)}

By Walter Radcliffe. William Heinemann Medical Books, Ltd. I947. Pp. 83. Price ros. 6d.

Although this small book retells a well-known story, it adds some new details, and has the great merit of relating the events of obstetric history to the background of general history. Dr. Radcliffe does not shirk the recording of dull facts whenever necessary, but the continuity of the various episodes is never lost and some excellent illustrations are added to a very readable text.

$$
\text { S.G.C. }
$$

\section{GARDINER'S HANDBOOK OF SKIN DISEASES}

Revised by JoHN KINNEAR, O.B.E., T.D., M.D., M.R.C.P.Ed., D.L. Fifth Edition. E. \& S. Livingstone, Ltd. 1948. Pp. 250. Price I5s.

It is always difficult to know what book on diseases of the skin to advise students to read. The standard volumes on the subject are too full and too frightening. Equally the practitioner who wishes to learn about a subject he probably neglected as a student can easily get lost in a maze of rare and unfamiliar diseases. A handbook of this size and at this very reasonable price is the ideal. What not to include must be a personal and difficult decision and criticism on that score would be unfair. Suffice it to say that it is eminently readable, well produced on good paper, and the illustrations, except for some of those in colour, are good. It is so readable that a charge can be raised of a certain looseness and vagueness of expression. The section on syphilis is sketchy and untidy; perhaps it would be better left to larger books or to books on venereology. It is perhaps a little surprising to find squamous epithelioma dismissed in a few lines; maybe this has been left to the books on surgery. The classification of 'rodent ulcers' into three types is a little arbitrary and few would agree that senile keratoses develop into basal-celled epitheliomata : they are precursors of the squamous-celled type. The section on naevi and angiomata also needs clarification. In a short book for students a certain amount of dogmatism is inevitable and permissible, even if the views expressed are not 